\title{
Impact of Pressure-based HACA Rates on Soot Formation in Varying-Pressure Coflow Laminar Diffusion Flames
}

\author{
Amin Mansouria, Leonardo Zimmer ${ }^{\mathrm{a}}$, Seth B. Dworkin ${ }^{\mathrm{a}}$, Nickolas A. Eaves ${ }^{\mathrm{b}^{*}}$ \\ aDepartment of Mechanical and Industrial Engineering, Ryerson University, 350 Victoria St., \\ Toronto, Ontario M5B 2K3, Canada \\ ${ }^{b}$ Department of Mechanical, Automotive and Materials Engineering, University of Windsor, 401 \\ Sunset Ave, Windsor, Ontario N9B 3P4, Canada
}

*E-mail address: nickolas.eaves@uwindsor.ca (Nickolas A. Eaves),

Phone number: +1 (519) 253-3000 ext. 5924 


\section{Abstract}

There are several processes to occur in soot formation and destruction for which some in the growth regime require a better understanding. In this work, a consistent surface reactivity model, developed in recent years, has been implemented across various sooting laminar flames at varying pressures. The surface reactivity function proposed by Khosousi and Dworkin [1] is employed in the present study. It is based on the temperature history of soot particles. As the functionally dependent model has been derived and validated for atmospheric pressure flames, there are discrepancies between simulation and experiment that can be observed as pressures vary. One reason for these discrepancies could be explained by the fact that chemical reaction rates for the soot growth mechanism at atmospheric combustion do not adequately characterize the kinetics at higher pressures. Based on a recently published study [2], the elementary reaction rates that compose the Hydogen-Addition-Carbon-Abstraction soot surface growth mechanism depend on pressure and an empirical pressure scaling factor to account for this pressure dependence has been introduced. It has been determined that after applying the new empirical pressure scaling factor for the soot growth mechanism, the performance of the functionally dependent surface reactivity model improves in the wing regions of the flame for pure-ethylene flames; however, there is minimal change on the wings for the nitrogen-diluted flames. Additionally, the quantity for soot concentration along the centerline of all flames is nearly independent of the surface reactivity model chosen and needs further investigation. For the flames investigated, it is concluded that pressure dependent 
HACA rates do not alleviate all discrepancies between the numerical and experimental results and that further work is required.

\section{Introduction on Surface Growth}

Although a large body of work on soot formation and oxidation has been conducted on atmospheric co-flow diffusion flames [1, 3-8], many gaps still remain with regard to soot modelling at elevated pressures. Moreover, due to high-pressure industrial applications of combustion, studying higher pressure flames is at the center of attention for academics and industry professionals. There is a sufficient number of experimental studies on high pressure co-flow diffusion flames for different fuels including ethylene and ethane [9-25] with only a few numerical studies [26-30]. Although experimental studies are necessary for validation and also to assess soot formation and oxidation behaviour, numerical studies are more suitable for large parametric studies due to lower cost and ability to investigate a wider range of parameters in a smaller timeframe. Further, numerical analyses are needed to fully understand the causes of the behaviour seen in the experiments.

Soot surface reactivity, which represents the percentage of soot particle sites that are available for chemical reaction, has been the subject of various studies $[1,5,7,28-33]$. For modelling this reactivity, either a single constant value or a function which captures different flame properties has been used. For example, a fixed parameter, soot surface reactivity, $\alpha$, of 0.078, was used in a previous work [5] in order to match the numerical results to the corresponding experimental data at atmospheric pressure. The concept of a temperature-history dependant $\alpha$ model has been tested in atmospheric co-flow diffusion 
flames $[1,7]$, while at higher pressures, researchers have only used constant $\alpha$ values for co-flow diffusion flames [26-30].

Eaves et al. [28, 29], Charest et al. [26, 27], and Liu et al. [30], numerically studied effects of different factors including pressure, conjugate heat transfer (CHT), gravity, and dilution on soot formation at higher pressures. Eaves et al. [29] conducted a sensitivity analysis on high pressure laminar coflow diffusion ethane-air flames to perceive the effect of different parameters including soot surface reactivity, and pressure on maximum soot concentration along the centerline of the flame, and along the pathline passing through the maximum soot volume fraction, $f_{v}$. They used different constant $\alpha$ values of $0.0195,0.039,0.078,0.156$, and 0.332 for the calculations. In the aforementioned study, it is shown that soot concentration along the pathline of maximum soot is more HACA surface-growth dominated than PAH condensation surface-growth dominated, while PAH condensation dominates the centreline of the flame. HACA surface growth refers to growth via chemical addition of carbon species (typically acetylene), while PAH condensation refers to the physical additional of PAHs to the surface. Also, as pressure is increased, the role of PAH condensation in surface growth becomes greater than that at lower pressures. These results led to later studies considering different constant $\alpha$ values and finding correlations between $\alpha$ and maximum $f_{v}$.

Contrary to [29, 30], Veshkini et al. [7] studied atmospheric pressure flames with a constant $\alpha$ for oxidation and with a functional $\alpha$ for formation which greatly improved the prediction of soot formation in those flames compared to a single constant $\alpha$ model. The function that Veshkini et al. proposed is based on temperature history, which depends on both 
temperature and residence time. Khosousi and Dworkin [1] applied the idea of temperature history to propose a novel functional $\alpha$ for both formation and oxidation rates. This model was tested for nine atmospheric pressure laminar coflow diffusion flames. Although the latter function was very successful in modelling different experimental data sets at atmospheric pressure, it has not yet been examined on higher pressures flames. Additionally, recent work has indicated that HACA surface growth rates depend on pressure [2]. To the current author's knowledge, there is no work assessing laminar coflow diffusion flames at varying pressures adopting a more predictive functional form for $\alpha$ and investigating pressure dependence of HACA surface growth rates.

To address this concern, recent experimental data from Karataș and Gülder [9] has been studied numerically. The numerical solutions are obtained with a constant value for $\alpha$, the Khosousi and Dworkin function for $\alpha$ [1], and the functional form of $\alpha$ and an empirical pressure dependent scaling factor for HACA rates. The solutions are compared to the experimental results for pure ethylene flames at pressures of 1, 3, 5, and $7 \mathrm{~atm}$ and for nitrogen diluted ethylene flames at pressures of 5, 10, 15, and $20 \mathrm{~atm}$. The purpose of the present study is to access any differences between the three numerical treatments for $\alpha$ and surface growth rates with varying pressure. It should be noted the improved surface growth model developed by Frenklach [34] is not included in this study, limiting the application of the present model to co-flow diffusion flames. 


\section{Soot Surface Reactivity}

It is widely accepted that PAHs are soot precursors. The most accepted model to develop multi-ring aromatics is Hydrogen-Abstraction-Carbon-Addition (HACA) [31, 35] mechanism. HACA begins with the abstraction of an $\mathrm{H}$ atom by another $\mathrm{H}$ atom existing near the surface of the PAH molecule. It is followed by carbon addition, by acetylene, to form further aromatic rings. This is displayed in Fig. 1 (please note the original version from [35] including reversibility is omitted here for clarity). Since soot particles are formed predominantly from aromatics, it is assumed that they have similar characteristics $[31,32,36]$. Thus, the chemical reaction sequences to build PAHs and soot are also presumed to be analogous. One of the major contributors to soot mass yield is surface growth of primary particles [31, 32]. Similar to PAH-HACA, soot particles grow via soot-HACA with the same reaction sequence.

Since the probability of an available $\mathrm{H}$ atom on the surface of soot molecules to start the HACA mechanism is not $100 \%$, not the entire soot surface area is available for chemical reaction. The portion of chemically active sites in soot particles, originally introduced in [31], which has been named 'soot surface reactivity' in recent studies [1], is a significant parameter in soot formation and the numerical value of this factor is between 0 and 1 , which 0 means there is no soot surface area is available, and 1 means the entire surface is accessible for chemical reaction. Soot surface reactivity, $\alpha$, was first introduced by Frenklach and Wang [31] to account for surface structure and reconcile the inaccuracies in numerical studies. 
Dworkin et al. [5] and Eaves et al. [29] showed that with a constant $\alpha$, the present numerical model is able to predict reasonable results; however, for each flame and burner configuration it needs to be retuned with a different $\alpha$ value. Based on the literature [31, 38, 39], soot surface reactivity depends on the temperature to which a soot particle has been exposed. Similarly, experimental studies $[39,40]$ define residence time as a significant factor in determining $\alpha$. In this sense, Veshkini et al. [7] proposed an $\alpha$ function, Eq. (1), which includes the concept of temperature history, or temperature aging:

$\alpha=\frac{6974.6}{T_{a}^{2}} \exp \exp \left(\frac{-88.06}{T_{a}}\right)$

where $T_{a}$ is thermal age and is defined as the integral of temperature with respect to residence time along a fluid parcel pathway, $S$, and is calculated as:

$T_{a}=\int_{s} T d t$

Khosousi and Dworkin [1] proposed a variation on that form of $\alpha$ which captures correctly the peak soot concentrations and smoking character for nine flames and burner configurations all at atmospheric pressure. Equation (3) is the mathematical form of this model:

$$
\alpha=\left(\frac{T_{a, \max }}{T_{a}}\right)^{2.2} \exp \left[2.4\left(0.85-\frac{T_{a, \max }}{T_{a}}\right)\right]
$$


where the $T_{a, \max }$ is the value for the thermal age at the location of maximum soot volume fraction.

Figure 2 displays contours of $\alpha$ of the Khosousi and Dworkin soot surface reactivity model [1] for the pure ethylene flames at varying pressures. This figure shows two important points; first, as pressure increases, the profile for $\alpha$ seems to be pressed towards the centerline of the flame as well as towards the nozzle of the flow field. Second, as pressure increases, $\alpha$ reaches its maximum at a lower height-above-the-burner (HAB) along the off-centerline areas of the flame. This may be due to the increase of $T_{a}$ at lower HABs with increasing pressure. The contours of the present $\alpha$ model [1] for the nitrogen diluted ethylene flames at varying pressures follow the same trend as well.

Unlike the Veshkini et al. model [7], the Khosousi and Dworkin equation [1] is capable of predicting both formation and oxidation adequately although it has not been examined for high-pressure flames. The other difference between these two models is the parameter $T_{a, \max }$, which changes as the location of peak $f_{v}$ varies. This functionality adjusts $\alpha$ for each flame without changing the soot surface reactivity model. Figure 3 displays the impact of $T_{a}$ on $\alpha$ for pure ethylene flames at varying pressures at two different locations on the centerline and the wing of the flame. It shows that $\alpha$ reaches approximately the same peak value at all pressures, then declines along both locations of the wing region and the centerline of the flames. Also, as pressure increases, $\alpha$ reaches this value at higher values of $T_{a}$. Again, 
repeating Fig. 3 for the nitrogen diluted ethylene flames result in the same trend as pressure increases.

The present study proceeds by examining the functional form of $\alpha$ proposed by Khosousi and Dworkin [1] for both formation and oxidation processes, then investigates advantages and drawbacks leading towards a more improved model. The temperature-history dependant $\alpha$ function does not lead to a significant increase in computational cost as it only needs to be evaluated every thousand or so time steps for steady systems.

The other important aspect that should be noted is, in most chemical kinetic mechanisms, reaction rates for HACA growth have been based on reaction rates at atmospheric pressure. Based on [31], the reaction rate for an individual reaction of $\mathrm{C}_{2} \mathrm{H}_{2}$ addition in the HACA-based soot surface growth and oxidation mechanism is as follows:

$R=\alpha k\left[C_{2} H_{2}\right]\left[C_{\text {soot }}^{\circ}\right]$

where $R$ is the reaction rate, $\alpha$ is the surface reactivity, $k$ is the global rate coefficient, and $\left[\mathrm{C}_{2} \mathrm{H}_{2}\right]$ and $\left[\mathrm{C}_{\text {soot }}{ }^{\circ}\right]$ are concentrations of acetylene and dehydrogenated sites. The concentration of dehydrogenated sizes is determined via a steady state assumption, which involves a ratio of all soot surface reactions producing dehydrogenated sites to those reducing dehydrogenated sites. Since the reaction rates for the overall HACA surface growth mechanism are those suitable for atmospheric pressure, they may not adequately characterize surface growth at varying pressures. A recent study by Frenklach et al. [2] indicates that surface growth reaction rates for the overall HACA surface growth mechanism depend on pressure. Based off 
of this study, a new model for the reaction rates for soot HACA growth is introduced and Eq. (4) is updated for higher pressure combustion as follows:

$R=\alpha(1+\log \log (p)) k\left[C_{2} H_{2}\right]\left[C_{s o o t}^{\circ}\right]$

where $p$ is the operating pressure, and $(1+\log \log (p))$ is the pressure scaling factor. It is important to note that the $(1+\log \log (p))$ expression is attributed to the pressure dependence of the HACA surface growth reaction rates, rather than the surface growth reactivity. The pressure scaling factor accounts for the pressure dependence of the acetylene addition rate, $k$, and $\left[C_{\text {soot }}^{\circ}\right]$. At 1 atm, Eq. (4) and Eq. (5) are identical and both predict the same reaction rate in an individual reaction of $\mathrm{C}_{2} \mathrm{H}_{2}$ addition in the HACA-based soot surface growth and oxidation mechanism. The form of $(1+\log \log (p))$ is utilized to capture pressure dependence based on the reaction of 2-naphthyl $+\mathrm{C} 2 \mathrm{H} 2 \rightarrow 2-\mathrm{N} 2$ from the supplementary material in [2]. For this reaction, a pressure dependence scaling factor of 4.8 is observed at $1375 \mathrm{~K}$ from $1 \mathrm{~atm}$ to $100 \mathrm{~atm}$. This is close to the pressure dependence scaling of 5.6 for the $(1+\log \log (p))$ factor. The simplified expression is utilized instead of the exact rates for 2-naphthyl $+\mathrm{C} 2 \mathrm{H} 2 \rightarrow 2-\mathrm{N} 2$ as the reaction is used as a template for the pressure dependence of the overall HACA surface growth reaction scheme. For the flames studied in this work, the value of the $(1+\log \log (p))$ expression varies from 1 at 1 atm to 4 at 20 atm. As both $\alpha$ and $(1+\log \log (p))$ are empirical parameters, they are combined into a single empirical parameter, $\alpha_{p}$. Hereinafter, the model with the atmospheric HACA growth rates and the temperature-history dependant $\alpha[1]$ is referred to as "Khosousi and Dworkin model" and the 
model with the pressure-based reaction rate of acetylene addition in the HACA mechanism and temperature-history dependant $\alpha$ is referred to as the "present model". These models are summarized in Table 1.

Tabel 1: Comparison of Khosousi and Dworkin model [1] and the present model

\begin{tabular}{|c|c|c|c|}
\hline Name & Soot HACA model & \multicolumn{2}{|c|}{$\alpha$ model } \\
\hline $\begin{array}{l}\text { Khosousi } \\
\text { and } \\
\text { Dworkin }\end{array}$ & $\begin{array}{l}\text { Atmospheric HACA growth rates } \\
\qquad R=\alpha k\left[\mathrm{C}_{2} \mathrm{H}_{2}\right]\left[\mathrm{C}_{\text {soot }}{ }^{\circ}\right]\end{array}$ & $\alpha=\left(\frac{T_{a, \max }}{T_{a}}\right)^{2.2} \exp$ & $2.4\left(0.85-\frac{T_{a, \max }}{T_{a}}\right)$ \\
\hline $\begin{array}{l}\text { Present } \\
\text { model }\end{array}$ & $\begin{array}{l}\text { Pressure-based HACA growth rates } \\
\qquad R=\alpha_{p} k\left[\mathrm{C}_{2} \mathrm{H}_{2}\right]\left[\mathrm{C}_{\text {soot }}^{\circ}\right]\end{array}$ & $\begin{array}{r}\alpha=\left(\frac{T_{a, \max }}{T_{a}}\right)^{2.2} \exp \\
\alpha_{p}=\alpha(1+1\end{array}$ & $\begin{array}{l}2.4\left(0.85-\frac{T_{a, \max }}{T_{a}}\right) \\
\operatorname{og} \log (p))\end{array}$ \\
\hline
\end{tabular}

\section{Flame and Model Description}

\subsection{Burner Configuration}

A brief description of the burner configuration that is modelled in the present work is given here; however, the details of the apparatus used for the experimental study can be found in $[9,11]$. A co-annular coflow laminar diffusion burner working at varying pressures has been studied. The inner diameter at the burner rim is $3 \mathrm{~mm}$. The thickness of the fuel tube decreases gradually from the rim to the edge of the fuel tube to prevent the formation of recirculation zones. The flames simulated in this chapter are the same as the flames in the experiment [9], including the pure ethylene flames at pressures of $1,3,5$, and 7 atm and $N_{2}$ diluted ethylene flames at pressures of 5, 10, 15 and 20 atm. For the pure ethylene flames, the mass flow rates 
of ethylene and air are kept at $0.48 \mathrm{mg} / \mathrm{s}$, and $340 \mathrm{mg} / \mathrm{s}$ respectively at all pressure levels. For the diluted flames, the mass flow rates of $\mathrm{N}_{2}$, ethylene, and air are kept at $0.96 \mathrm{mg} / \mathrm{s}, 0.48$ $\mathrm{mg} / \mathrm{s}$, and $340 \mathrm{mg} / \mathrm{s}$ respectively at all pressure levels.

Figure 4 displays the ethylene-air flame pictures and the schematic representation of the burner and the boundary conditions. Considering Fig. 4, to further explain the choice of inlet boundary condition, one option is to move the bottom boundary of the computational domain down below the fuel tube exit. This would necessitate the modelling of the solid tube material as either adiabatic, or thermally participating. The term conjugate heat transfer (CHT) is used to describe processes which involve the combination of heat transfer between solids and fluids. An anchored flame will heat the fuel tube, leading to $\mathrm{CHT}$, although permitting $\mathrm{CHT}$ in the model does not necessarily mean that it would occur. Although CHT has been utilized with the CoFlame code in the past [28] with great additional computational cost, it is not considered in the current study. Also in consultation with the authors of the experimental paper [9], it was noted that full characterization of liftedness and heat conduction back down toward the burner was not conducted. Therefore, $\mathrm{CHT}$ is not conducted in the present work.

\subsection{Numerical Model}

The fully coupled governing equations for mass, momentum, energy, and species mass fraction are solved using the CoFlame code [41]. The details of gaseous phase governing equations and boundary conditions can be found in [41]. The computational domain is formed as a non-uniform axisymmetric grid, with 150 control volumes in the radial direction $(r)$ and 400 
control volumes in the axial direction $(z)$, with the resolution of $d r=0.013 \mathrm{~mm}$ and $d z=0.016$ $\mathrm{mm}$ in the flame region.

A fixed soot sectional model is used, in which the soot particle mass is divided into thirty-five sections logarithmically. The soot particle dynamics model consists of inception, Hydrogen Abstraction Carbon Addition (HACA), Polycyclic Aromatic Hydrocarbon (PAH) condensation, coagulation, and fragmentation. In the current model, chemical PAH addition is not considered. It should be noted that recently available updated kinetics for soot surface oxidation [34, 42] are not included in this study, and the soot surface reaction scheme introduced in [32] with slight modifications from [41] is adopted (please see Supplementary Material for the reaction scheme). The soot sectional model solves two equations per section to obtain number densities of aggregates and primary particles. The chemical mechanism used in the present work is a modified version of an earlier mechanism presented in $[5,43]$, which is described in detail in [44].

\section{Results and Discussion}

\subsection{Pure Ethylene Flames}

A comparison between the simulation results and the experimental data [9] for pure ethylene flames is made for the maximum soot volume fraction at pressures from 1 to 7 atm,

which is shown in Fig. 5. The uncertainty in soot volume fraction for the experimental data is taken as $40 \%$ [9], which is comparable to other experimental studies at elevated pressures. Figure 5 shows some important aspects; first, the model with a constant $\alpha$ value of 0.5 follows 
closely the trend of the experimental values; however, it only predicts the peak $f_{v}$ of the experimental data within the uncertainty for a pressure of 3 atm. Second, although Khosousi and Dworkin model [1] leads to a prediction of higher peak $f_{v}$ compared to the constant $\alpha$ model, it is again only able to predict the peak $f_{v}$ of the experimental data within the uncertainty at 3 atm. Third, both the model with an constant $\alpha$ value of 0.5 and Khosousi and Dworkin model [1] predict the experimental results for the other three pressures in the same order of magnitude. Forth, the present model predicts the peak $f_{v}$ of the experimental data within the uncertainty at all pressures of $1,3,5$, and 7 atm. The ratios of the numerical result from Khosousi and Dworkin model [1] and the present model to the experiment for maximum soot volume fraction are 0.54 and 1.15 at 1 atm, 0.78 and 1.15 at 3 atm, 0.48 and 1.01 at 5 atm, and 0.35 and 0.69 at 7 atm respectively.

A comparison between the experimental and the numerical results for the peak values of soot volume fractions are summarized in Table 2 . The numbers in the brackets in the experimental column are lower and upper bounds of the experimental data range. Table 2 shows that only the present model is capable of predicting the maximum soot concentration within the experimental uncertainty for all pressures from 1 to 7 atm.

Table 2: Comparison of peak soot volume fraction values ( $\mathrm{ppm}$ ) between experimental and numerical results for the pure ethylene flames.

\begin{tabular}{ccccc}
\hline Flames & Exp. [9] & $\boldsymbol{\alpha}=\mathbf{0 . 5}$ & Khosousi and Dworkin [1] & Present model \\
\hline 1 atm & {$[0.45,1.05]$} & 0.28 & 0.40 & 0.86 \\
3 atm & {$[9,21]$} & 9.8 & 11.7 & 17.4 \\
5 atm & {$[43,101]$} & 29.5 & 32.4 & 72.2 \\
7 atm & {$[104,243]$} & 54.1 & 60.3 & 120.4 \\
\hline
\end{tabular}


An assessment of the overall shape of the flame is necessary to ensure that simulations predict the physical characteristics of the flame such as flame length. Flame length, which is defined by the axial location where the percent stoichiometric air is $100 \%$, is inversely proportional to flame temperature [45]. For this reason, flame temperature is an indicator of flame length, and Fig. 6 displays a comparison of temperature contours for the experiment and the present model.

Based on the temperature field which is displayed in Fig. 6, pressure has a significant impact on the temperature map. When considering the overall flame shape, the simulation reproduces what is seen in the experiment with acceptable accuracy. As pressure increases, the flame becomes thinner and the flame length increases, and the location of the peak temperature changes from the inner part of the flame to the wings. The maximum values for the temperature obtained from the present model are $2077,2041,1978$, and $1998 \mathrm{~K}$ at $1,3,5$, and 7 atm, respectively. The maximum values for the temperature obtained from the experiment [9] are 2080, 2021, 1949, and $1963 \mathrm{~K}$ at 1, 3, 5, and 7 atm, respectively. It should also be noted that the experimental temperature map does not have smooth edges which is due to a large drop from the flame temperature to the coflow air temperature. This comparison indicates that the simulation can capture the trend for temperature. For all pressure levels except $1 \mathrm{~atm}$, the simulated flame lengths are slightly smaller than the experimental ones, which can contribute to a different soot formation field than the experimental ones. Despite these differences, the simulation captures the correct maximum temperature and trend for the temperature field compared to the experimental result. 
Furthermore, Fig. 7 displays a comparison of the soot yield percent versus the height-above-the-burner $(\mathrm{HAB})$ between the experimental and the simulation results brings more detailed information about the impact of utilizing various soot surface reactivity models.

Figure 7 shows some important points; first, since at 1 atm, there is no difference between Khosousi and Dworkin model [1] and the present model, and the results of simulation utilizing both models are exactly the same. Second, as pressure increases, the prediction of the soot yield percent for the model with a constant $\alpha$ value of 0.5 and Khosousi and Dworkin model [1] starts to cluster together and to deviate from the results utilizing the present model. Third, the present model leads to a better prediction of the soot yield percent among the three soot surface reactivity models. Fourth, as pressure increases, the effectiveness of the present model in predicting the soot yield percent becomes more significant. Lastly, the present model leads to a more accurate prediction in the formation region compared to the oxidation region. Formation region is simply defined by the region of the flame in which soot particles grow and their masses increase, whereas in oxidation region, soot particles and aggregates reduce in size.

In the experimental study [9], the maximum soot volume fraction at 1 and 3 atm lays along the centerline of the flame which is not captured with the numerical model. Therefore, a comparison of $f_{v}$ along the centerline between the experimental study [9] and the simulations utilizing a constant $\alpha$ value of 0.5 , Khosousi and Dworkin model [1], and the present model, which is displayed in Fig. 8, provides insight into the discrepancy.

As can be observed in Fig. 8, as pressure increases, all models underpredict the location of peak soot concentration on the centerline. It also shows that despite underpredicting $f_{v}$, all 
models lead to the prediction of soot concentration along the centerline of the flames within the correct order of magnitude at all pressures. It is noteworthy that due to the cumbersome practical accessibility to trace the pathline of peak $f_{v}$, experimental data for soot concentration along that pathline is not available for comparison purposes with the simulation results. Overall, the effect of pressure dependent rates on predicted centerline soot volume fractions is negligible.

Comparing Fig. 7 and Fig. 8 shows that the most important difference between the results of the three soot surface reactivity models is at the wing region, where the present model shows a greater increase in $f_{v}$ compared to the other two models. However, along the centerline of the flames, the present model leads to a decrease in $f_{v}$ as pressure increases, albeit a negligible one, due to the domination of PAH condensation and not HACA, which is consistent with the results of the study of Eaves et al. [29]. The present model still predicts HACA surface growth to be dominate on the wings, and PAH condensation to be dominant on the centerline. The numerical results utilizing the present model predict the peak $f_{v}$ at the wings at all pressures, which is in contrast with the experiment of the 1 and 3 atm pure ethylene flames [9]. The experiment shows that the peak value for these flames lays at the centerline of the flames.

\section{2. $N_{2}$ Diluted Ethylene Flames}

The effect of soot surface reactivity is also analyzed for cases of $\mathrm{N}_{2}$ diluted ethylene flames at a pressure range of $5,10,15$, and $20 \mathrm{~atm}$. Overall features are similar to the pure ethylene flames presented in the previous section. A comparison between the simulation 
results and the experimental data [9] for $\mathrm{N}_{2}$ diluted ethylene flames is made for the maximum soot volume fraction at pressures from 5 to 20 atm, which is shown in Fig. 9. Again, the uncertainty in soot volume fraction for the experimental data is taken as $40 \%$ [9].

Figure 9 shows some important aspects; first, all soot surface reactivity models are able to predict the peak $f_{v}$ of the experimental data within the experimental uncertainty at all pressures. Second, as pressure increases, the prediction of peak $f_{v}$ for all the three $\alpha$ models lumps together; however, the present model predicts a higher peak $f_{v}$ compared to the other two soot surface reactivity models at all pressures, which is similar to the results of the pure ethylene flames. The ratios of the numerical result utilizing Khosousi and Dworkin model [1] and the present model to the experiment for maximum soot volume fraction is 1.24 and 1.45 at 5 atm, 1.01 and 1.14 at 10 atm, 0.76 and 0.84 at 15 atm, and 0.67 and 0.74 at 20 atm respectively. The peak values of soot volume fractions and the comparison between the experimental and the numerical results are summarized in Table 3. Numbers in the brackets in the experimental column are lower and upper bounds of the experimental data range. Overall, Figure 9 and Table 3 demonstrate that the effect of pressure dependent HACA rates on peak soot volume fraction for the nitrogen-diluted flames is negligible and well within experimental error.

Table 3: Comparison of peak soot volume fraction values ( $\mathrm{ppm}$ ) between experimental and numerical results for the $\mathrm{N}_{2}$ diluted ethylene flames.

\begin{tabular}{ccccc}
\hline Flames & Exp. [9] & $\boldsymbol{\alpha}=\mathbf{0 . 5}$ & Khosousi and Dworkin [1] & Present model \\
\hline $5 \mathrm{~atm}$ & {$[8,19]$} & 12.6 & 16.8 & 18.9 \\
$10 \mathrm{~atm}$ & {$[39,91]$} & 57.1 & 66.8 & 75.1 \\
$15 \mathrm{~atm}$ & {$[96,225]$} & 128.5 & 122.3 & 134.5
\end{tabular}


The temperature fields for $\mathrm{N}_{2}$ diluted ethylene flames are displayed in Fig. 10 in order to check the overall shape of the flames. The present model reproduces the overall shape of the flames seen in the experiment with acceptable accuracy. As pressure increases, the flame becomes thinner and the flame length increases, and the location of the peak temperature shifts from the inner part of the flame to the wings. The maximum values for the temperature obtained from the simulation applying the present model are 1988, 1959, 1951, and $1946 \mathrm{~K}$ at $5,10,15$, and 20 atm, respectively. The maximum values for the temperature obtained from the experiment [9] are 2022, 1982, 1955, and $1948 \mathrm{~K}$ at 5, 10, 15, and 20 atm, respectively. Similar to the pure ethylene flames, this comparison indicates that the simulation can capture the trend for temperature. For all simulations, the flame lengths are slightly smaller than the experimental ones, which can contribute to a different soot formation field than the experimental ones. Despite that, the simulation captures the correct maximum temperature and trend for the temperature field compared to the experimental result.

A comparison of the soot yield percent versus HAB between the experimental and the simulation results reveals more detailed information about the impact of utilizing various $\alpha$ models on the nitrogen diluted ethylene flames. This comparison which is displayed in Fig. 11, shows some important points; first, all models lead to a more accurate prediction in the formation region than in the oxidation section. Second, as pressure increases, the prediction of the soot yield percent for the model with a constant $\alpha$ value of 0.5 and Khosousi and Dworkin model [1] starts to cluster together and to deviate from the results of the simulation utilizing 
the present model. Lastly, although all models underpredict the location of peak soot yield percent compared to the experimental result, the present model leads to a better prediction of the maximum soot yield percent at all pressures, although the effect is minor. This underprediction of the location of peak soot yield percent may be due to the smaller flame length in the simulations and underprediction on the centerline of the flames.

Once again, for a more thorough investigation of the impact of these three models on soot formation and oxidation, a comparison of $f_{v}$ as a function of $\mathrm{HAB}$ along the centerline between the experimental study [9] and the simulations implementing a constant $\alpha$ value of 0.5 , Khosousi and Dworkin model [1], and the present model for $\mathrm{N}_{2}$ diluted ethylene flames at different pressures from 5 to 20 atm is required. This comparison is displayed in Fig. 12.

As can be observed in Fig. 12, as pressure increases, all models capture the location of peak soot concentration on the centerline more precisely. It also shows that despite underpredicting $f_{v}$, all models lead to the prediction of soot concentration along the centerline of the flames within the same order of magnitude at all pressures. Although all three surface reactivity models underpredict the quantity and the location of peak soot concentration, they capture the correct trend of soot formation and decomposition as the pressure increases. At 5 atm, all three models predict a very similar profile for $f_{v}$ with respect to HAB. As pressure increases the results of these three models deviate from each other in a way that Khosousi and Dworkin model [1] predicts the highest $f_{v}$, then the present model and the constant $\alpha$ model consecutively. It again should be noted that due to the cumbersome practical accessibility to trace the pathline of peak $f_{v}$, experimental data for soot concentration along that pathline is not 
available for comparison purposes with the simulation results. Taken as a whole, the effect of pressure dependent HACA rates is negligible for the nitrogen-diluted flames.

\section{Conclusions}

The effect of surface reactivity of soot particles in pure ethylene flames at pressures of $1,3,5$, and 7 atm and $N_{2}$ diluted ethylene flames at pressures of $5,10,15$, and 20 atm is studied. A new pressure scaling factor for the HACA surface growth mechanism is introduced and is evaluated for use in varying pressure flames. The employed soot surface reactivity model in the present study is the same as in the study conducted by Khosousi and Dworkin [1]. The same surface reactivity model is implemented for both formation and oxidation processes, but its impact on oxidation in these flames is negligible which is the same as that on the atmospheric flames in a previous study [1]. For pure ethylene flames, Khosousi and Dworkin model [1] is capturing qualitative trends, while the distribution and quantities still remain the subject of further inquiry. The present model is able to predict the peak $f_{v}$ within the experimental uncertainty at all pressures; however, this model could not capture the peak $f_{v}$ along the centerline of the $1 \mathrm{~atm}$ pure ethylene flame correctly. Since none of the models could capture the maximum soot concentration along the centerline of the 1 atm flame, this inconsistency highlights the need to better understand the physical processes that are occurring in the central/pyrolysis region of that flame. As pressure increases the effectiveness of the present model in predicting the soot yield percent becomes more significant. For the $\mathrm{N}_{2}$ diluted ethylene flames, all of the three models capture the peak $f_{v}$ within the experimental uncertainty; however, the present model leads to a prediction of higher values compared to the 
other two models. Moreover, altering the soot surface reactivity models does not lead to any significant differences in prediction of $f_{v}$ along the centerline of the flame for both pure and nitrogen diluted ethylene flames. For the flames investigated, it is concluded that pressure dependent HACA surface growth mechanism rates do not alleviate all discrepancies between the numerical and experimental results and that further work is required. One area of current and future inquiry relates back to the model for inception, and the potential participation of PAHs with aliphatic chains, which may work to change the distribution of soot within the flame. Additionally, the present model should be updated to include the improved surface growth models developed in $[34,42]$ and applied to diffusion and pre-mixed flames. The pressure dependence of $\mathrm{O} 2$ oxidation rates and the effect on soot formation should be investigated as well.

\section{Acknowledgements}

This research was undertaken, in part, thanks to funding from the Canada Research Chairs programme. The authors acknowledge NSERC of Canada for additional financial support. Computations were performed on the Niagara supercomputer at the SciNet HPC Consortium. SciNet is funded by: The Canada Foundation for Innovation under the auspices of Compute Canada; the Government of Ontario; Ontario Research Fund - Research Excellence; and the University of Toronto. 


\section{Supplementary Material}

Table S1: HACA-based soot surface growth and oxidation reactions [32]

\begin{tabular}{lllll}
\hline No. & Reaction & $\begin{array}{l}A \\
\left(\mathrm{~cm}^{3} \mathrm{~mol}^{-1} \mathrm{~s}^{-1}\right)\end{array}$ & $b$ & $\begin{array}{l}E_{a} \\
(\mathrm{kcal} / \mathrm{mol})\end{array}$ \\
\hline S1 & $\mathrm{C}_{\text {soot }}-\mathrm{H}+\mathrm{H} \rightleftharpoons \mathrm{C}_{\text {soot }} \cdot+\mathrm{H}_{2}$ & $4.2 \times 10^{13}$ & 0.0 & 13.0 \\
S2 & $\mathrm{C}_{\text {soot }}-\mathrm{H}+\mathrm{OH} \rightleftharpoons \mathrm{C}_{\text {soot }} \cdot+\mathrm{H}_{2} \mathrm{O}$ & $1.0 \times 10^{10}$ & 0.73 & 1.43 \\
$\mathrm{~S} 3$ & $\mathrm{C}_{\text {soot }} \cdot+\mathrm{H} \rightarrow \mathrm{C}_{\text {soot }}-\mathrm{H}$ & $2.0 \times 10^{13}$ & 0.0 & 0.0 \\
S4 & $\mathrm{C}_{\text {soot }} \cdot+\mathrm{C}_{2} \mathrm{H}_{2} \rightarrow \mathrm{C}_{\text {soot }}-\mathrm{H}+\mathrm{H}$ & $8.0 \times 10^{7}$ & 1.56 & 3.8 \\
S5 & $\mathrm{C}_{\text {soot }} \cdot+\mathrm{O}_{2} \rightarrow 2 \mathrm{CO}+$ product & $2.2 \times 10^{12}$ & 0.0 & 7.5 \\
S6 & $\mathrm{C}_{\text {soot }}-\mathrm{H}+\mathrm{OH} \rightarrow \mathrm{CO}+$ product & & $\gamma_{\mathrm{OH}}=0.13$ & \\
\hline
\end{tabular}




\section{Bibliography}

[1] A. Khosousi, S.B. Dworkin, Soot surface reactivity during surface growth and oxidation in laminar diffusion flames, Combustion and Flame 162 (2015) 4523-4532.

[2] M. Frenklach, R.I. Singh, A.M. Mebel, On the low-temperature limit of HACA, Proceedings of the Combustion Institute 37 (2019) 969-976.

[3] R.J. Santoro, T.T. Yeh, J.J. Horvath, H.G. Semerjian, The Transport and Growth of Soot Particles in Laminar Diffusion Flames, Combustion Science and Technology 53 (1987) 89-115.

[4] Q. Zhang, H. Guo, F. Liu, G.J. Smallwood, M.J. Thomson, Modeling of soot aggregate formation and size distribution in a laminar ethylene/air coflow diffusion flame with detailed PAH chemistry and an advanced sectional aerosol dynamics model, Proceedings of the Combustion Institute 32 (2009) 761-768.

[5] S.B. Dworkin, Q. Zhang, M.J. Thomson, N.A. Slavinskaya, U. Riedel, Application of an enhanced PAH growth model to soot formation in a laminar coflow ethylene/air diffusion flame, Combustion and Flame 158 (2011) 1682-1695.

[6] N.A. Slavinskaya, P. Frank, A modelling study of aromatic soot precursors formation in laminar methane and ethene flames, Combustion and Flame 156 (2009) 1705-1722.

[7] A. Veshkini, S.B. Dworkin, M.J. Thomson, A soot particle surface reactivity model applied to a wide range of laminar ethylene/air flames, Combust. Flame 161 (2014) 3191-3200.

[8] Q. Zhang, M.J. Thomson, H. Guo, F. Liu, G.J. Smallwood, A numerical study of soot aggregate formation in a laminar coflow diffusion flame, Combustion and Flame 156 (2009) 697-705.

[9] A.E. Karataş, Ö.L. Gülder, Dependence of sooting characteristics and temperature field of co-flow laminar pure and nitrogen-diluted ethylene-air diffusion flames on pressure, Combustion and Flame 162 (2015) 1566-1574.

[10] A.E. Karataş, Ö.L. Gülder, Effects of carbon dioxide and nitrogen addition on soot processes in laminar diffusion flames of ethylene-air at high pressures, Fuel 200 (2017) 76-80. [11] K.A. Thomson, Ö.L. Gülder, E.J. Weckman, R.A. Fraser, G.J. Smallwood, D.R. Snelling, Soot concentration and temperature measurements in co-annular, nonpremixed CH4/air laminar flames at pressures up to $4 \mathrm{MPa}$, Combustion and Flame 140 (2005) 222-232.

[12] A.M. Vargas, Ö.L. Gülder, Pressure dependence of primary soot particle size determined using thermophoretic sampling in laminar methane-air diffusion flames, Proceedings of the Combustion Institute 36 (2017) 975-984.

[13] L.L. McCrain, W.L. Roberts, Measurements of the soot volume field in laminar diffusion flames at elevated pressures, Combustion and Flame 140 (2005) 60-69.

[14] P.M. Mandatori, Ö.L. Gülder, Soot formation in laminar ethane diffusion flames at pressures from 0.2 to 3.3MPa, Proceedings of the Combustion Institute 33 (2011) 577-584. [15] P.M. Mandatori, Soot Formation in Ethane-air Coflow Laminar Diffusion Flames at Elevated Pressures, Library and Archives Canada = Bibliothèque et Archives Canada2006. [16] A.E. Karataş, Ö.L. Gülder, Soot formation in high pressure laminar diffusion flames, Progress in Energy and Combustion Science 38 (2012) 818-845.

[17] P.H. Joo, B. Gigone, E.A. Griffin, M. Christensen, Ö.L. Gülder, Soot primary particle size dependence on combustion pressure in laminar ethylene diffusion flames, Fuel 220 (2018) 464-470. 
[18] H.I. Joo, Ö.L. Gülder, Experimental study of soot and temperature field structure of laminar co-flow ethylene-air diffusion flames with nitrogen dilution at elevated pressures, Combustion and Flame 158 (2011) 416-422.

[19] H.I. Joo, Ö.L. Gülder, Soot formation and temperature field structure in co-flow laminar methane-air diffusion flames at pressures from 10 to 60atm, Proceedings of the Combustion Institute 32 (2009) 769-775.

[20] H. Guo, Z. Gu, K.A. Thomson, G.J. Smallwood, F.F. Baksh, Soot formation in a laminar ethylene/air diffusion flame at pressures from 1 to 8atm, Proceedings of the Combustion Institute 34 (2013) 1795-1802.

[21] Ö.L. Gülder, G. Intasopa, H.I. Joo, P.M. Mandatori, D.S. Bento, M.E. Vaillancourt, Unified behaviour of maximum soot yields of methane, ethane and propane laminar diffusion flames at high pressures, Combustion and Flame 158 (2011) 2037-2044.

[22] E.A. Griffin, Ö.L. Gülder, Soot formation in diluted laminar ethene, propene and 1-butene diffusion flames at elevated pressures, Combustion and Flame 197 (2018) 378-388.

[23] E.A. Griffin, M. Christensen, Ö.L. Gülder, Effect of ethanol addition on soot formation in laminar methane diffusion flames at pressures above atmospheric, Combustion and Flame 193 (2018) 306-312.

[24] B. Gigone, A.E. Karataş, Ö.L. Gülder, Soot aggregate morphology in coflow laminar ethylene diffusion flames at elevated pressures, Proceedings of the Combustion Institute 37 (2019) 841-848.

[25] M. Commodo, P.H. Joo, G. De Falco, P. Minutolo, A. D’Anna, Ö.L. Gülder, Raman Spectroscopy of Soot Sampled in High-Pressure Diffusion Flames, Energy \& Fuels 31 (2017) 10158-10164.

[26] M.R.J. Charest, C.P.T. Groth, Ö.L. Gülder, A numerical study on the effects of pressure and gravity in laminar ethylene diffusion flames, Combustion and Flame 158 (2011) 1933-1945.

[27] M.R.J. Charest, C.P.T. Groth, Ö.L. Gülder, Effects of gravity and pressure on laminar coflow methane-air diffusion flames at pressures from 1 to 60 atmospheres, Combustion and Flame 158 (2011) 860-875.

[28] N.A. Eaves, M.J. Thomson, S.B. Dworkin, The Effect of Conjugate Heat Transfer on Soot Formation Modeling at Elevated Pressures, Combust. Sci. Technol. 185 (2013) 1799-1819. [29] N.A. Eaves, A. Veshkini, C. Riese, Q. Zhang, S.B. Dworkin, M.J. Thomson, A numerical study of high pressure, laminar, sooting, ethane-air coflow diffusion flames, Combust. Flame 159 (2012) 3179-3190.

[30] F. Liu, A.E. Karataş, Ö.L. Gülder, M. Gu, Numerical and experimental study of the influence of CO2 and N2 dilution on soot formation in laminar coflow C2H4/air diffusion flames at pressures between 5 and 20atm, Combust. Flame 162 (2015) 2231-2247.

[31] M. Frenklach, H. Wang, Detailed modeling of soot particle nucleation and growth, Symposium (International) on Combustion 23 (1991) 1559-1566.

[32] J. Appel, H. Bockhorn, M. Frenklach, Kinetic modeling of soot formation with detailed chemistry and physics: laminar premixed flames of C2 hydrocarbons, Combustion and Flame 121 (2000) 122-136.

[33] J.B. Howard, Carbon addition and oxidation reactions in heterogeneous combustion and soot formation, Symposium (International) on Combustion 23 (1991) 1107-1127.

[34] M. Frenklach, New form for reduced modeling of soot oxidation: Accounting for multi-site kinetics and surface reactivity, Combustion and Flame 201 (2019) 148-159. 
[35] M. Frenklach, D.W. Clary, J. Gardiner, W.C., S.E. Stein, Detailed kinetic modeling of soot formation in shock-tube pyrolysis of acetylene, Proceedings of the Combustion Institute 20 (1985) 887-901.

[36] M. Frenklach, Reaction mechanism of soot formation in flames, Physical Chemistry Chemical Physics 4 (2002) 2028-2037.

[37] I. Cherchneff, The formation of polycyclic aromatic hydrocarbons in evolved circumstellar environments, (2011).

[38] R.A. Dobbins, R.A. Fletcher, H.C. Chang, The evolution of soot precursor particles in a diffusion flame, Combust. Flame 115 (1998) 285-298.

[39] C.J. Dasch, The decay of soot surface growth reactivity and its importance in total soot formation, Combust. Flame 61 (1985) 219-225.

[40] M. Alfè, B. Apicella, R. Barbella, J.N. Rouzaud, A. Tregrossi, A. Ciajolo, Structure-property relationship in nanostructures of young and mature soot in premixed flames, Proc. Combust. Inst. 32 (2009) 697-704.

[41] N.A. Eaves, Q. Zhang, F. Liu, H. Guo, S.B. Dworkin, M.J. Thomson, CoFlame: A refined and validated numerical algorithm for modeling sooting laminar coflow diffusion flames, Computer Physics Communications 207 (2016) 464-477.

[42] M. Frenklach, Z. Liu, R.I. Singh, G.R. Galimova, V.N. Azyazov, A.M. Mebel, Detailed, sterically-resolved modeling of soot oxidation: Role of $\mathrm{O}$ atoms, interplay with particle nanostructure, and emergence of inner particle burning, Combustion and Flame 188 (2018) 284-306.

[43] N.A. Slavinskaya, U. Riedel, S.B. Dworkin, M.J. Thomson, Detailed numerical modeling of PAH formation and growth in non-premixed ethylene and ethane flames, Combust. Flame 159 (2012) 979-995.

[44] V. Chernov, M.J. Thomson, S.B. Dworkin, N.A. Slavinskaya, U. Riedel, Soot formation with $\mathrm{C} 1$ and $\mathrm{C} 2$ fuels using an improved chemical mechanism for PAH growth, Combust. Flame 161 (2014) 592-601.

[45] S.R. Turns, An Introduction to Combustion: Concepts and Applications, McGraw-Hill2012. 


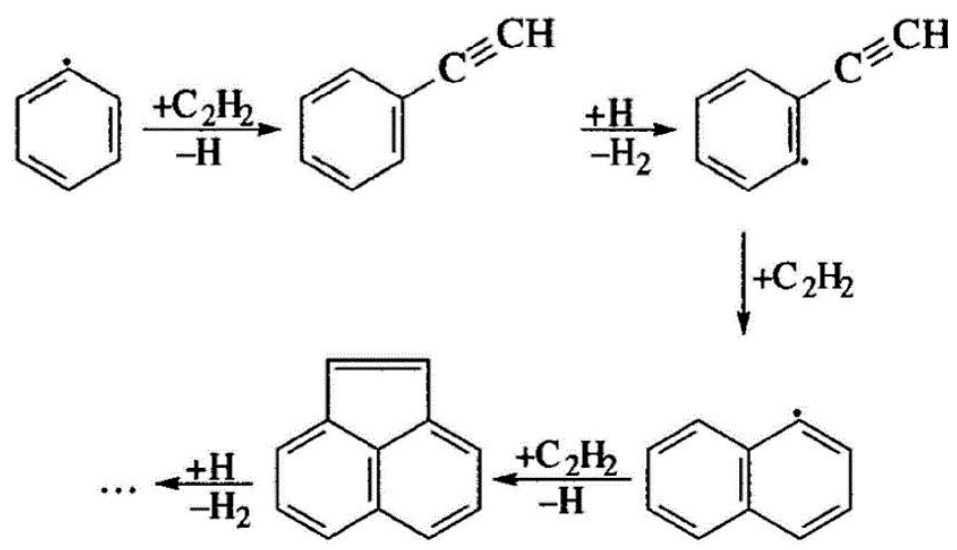

Figure 1: Formation of multi-ringed aromatics through HACA sequence (Reprinted from [37])

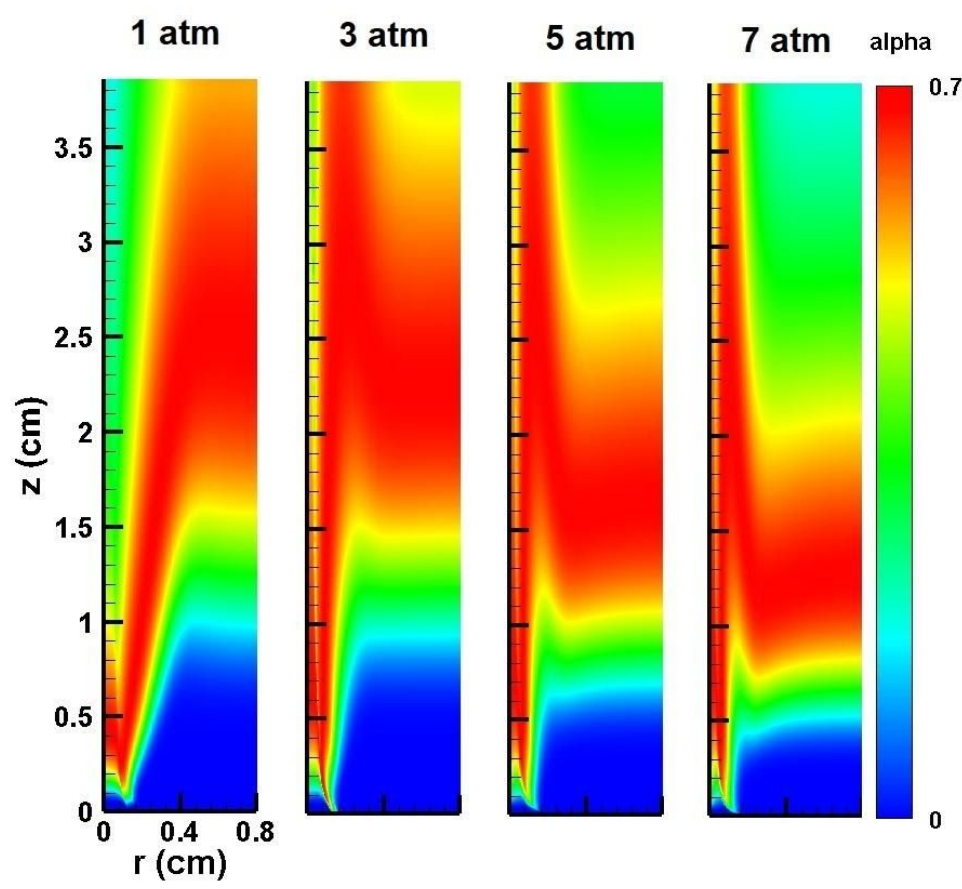

Figure 2: Soot surface reactivity, $\alpha$ function [1] contours of pure ethylene flames at different pressures of $1,3,5$, and $7 \mathrm{~atm}$ 

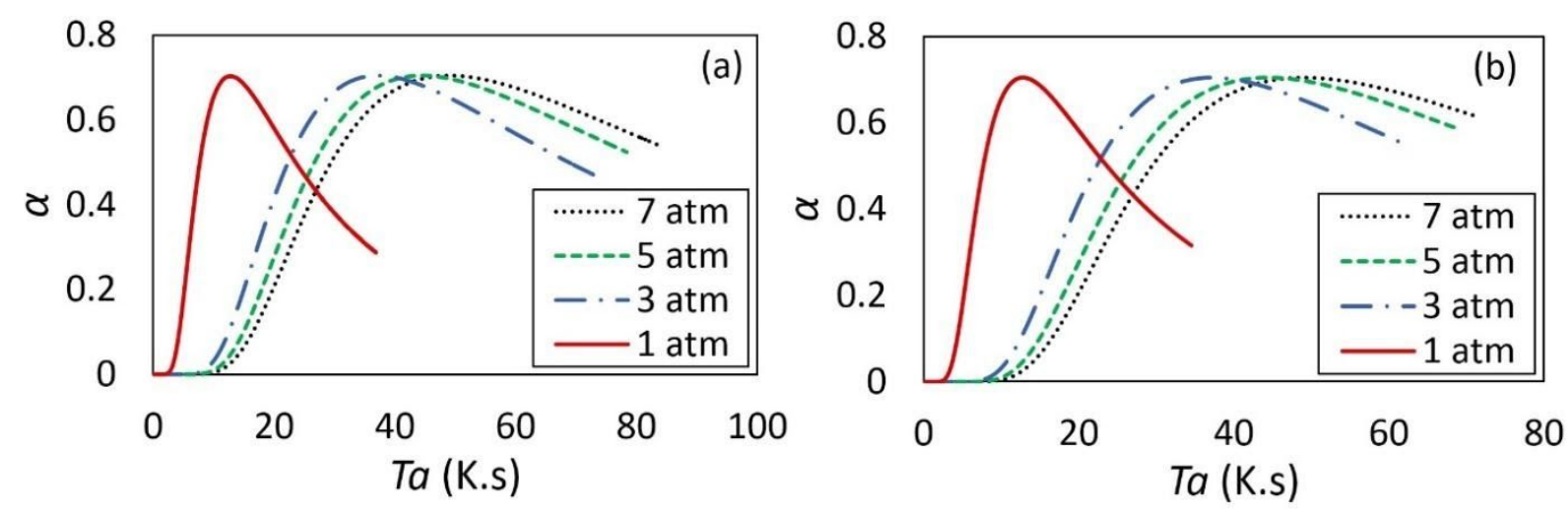

Figure 3: Comparison of the functional form of $\alpha$ [1] versus the temperature-history, a) along the pathline of maximum $f_{v}$, and b) along the centerline of the flame for pure ethylene flames at different pressures of $1,3,5$, and $7 \mathrm{~atm}$

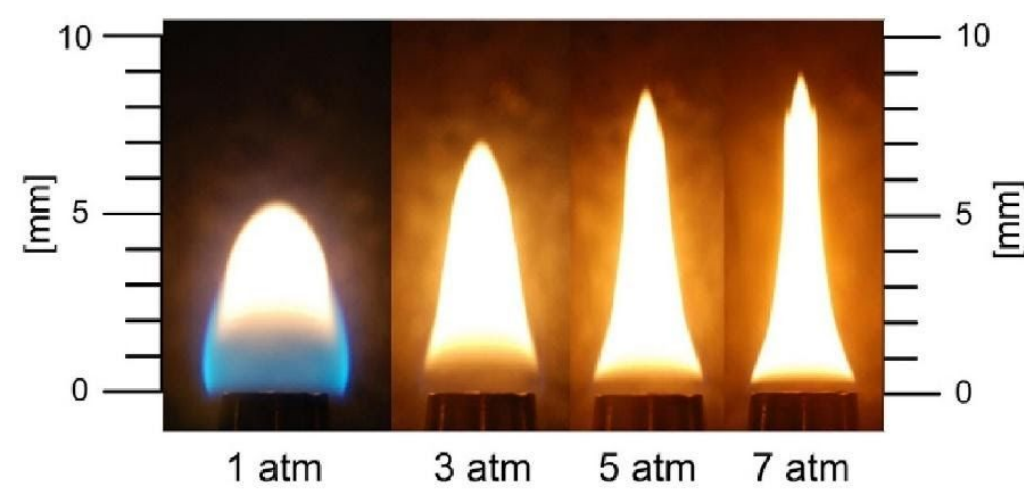

(a)

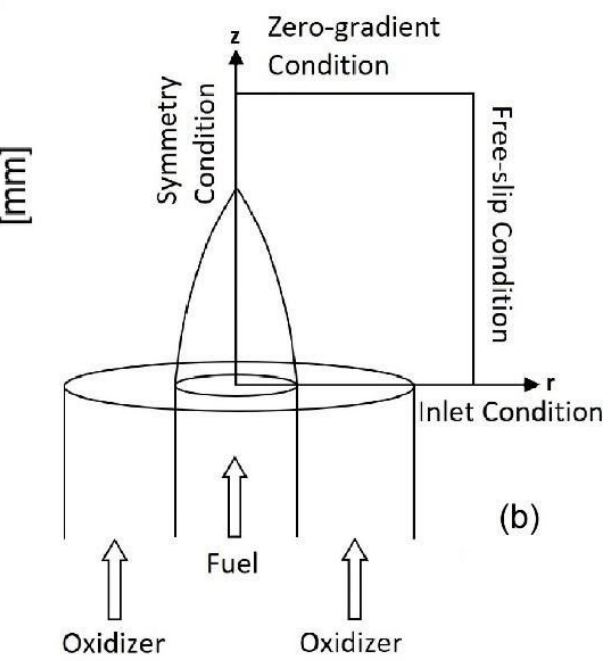

Figure 4: Flame and burner configuration, a) A still photo of the laminar co-annular ethylene-air flame at pressures up to $7 \mathrm{~atm}$ (Reprinted from [9]), b) Schematic representation of the burner and flame, including coordinate axes and computational domain boundaries. (Image is not drawn to scale) 


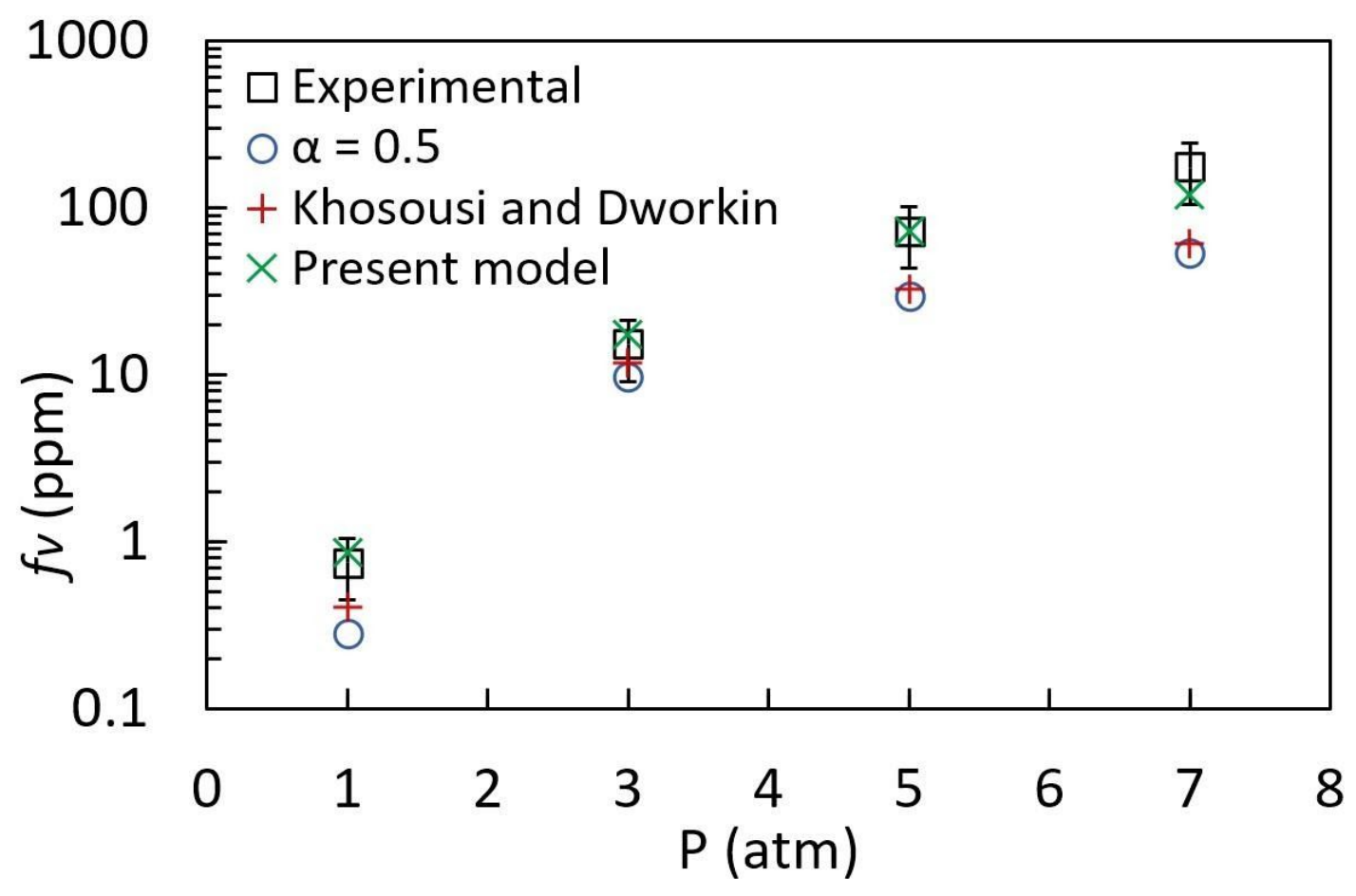

Figure 5: Comparison of global maximum soot volume fraction in the numerical study for constant $\alpha$ value of 0.5 , Khosousi and Dworkin model [1], and the present model, with the experimental study [9]. 


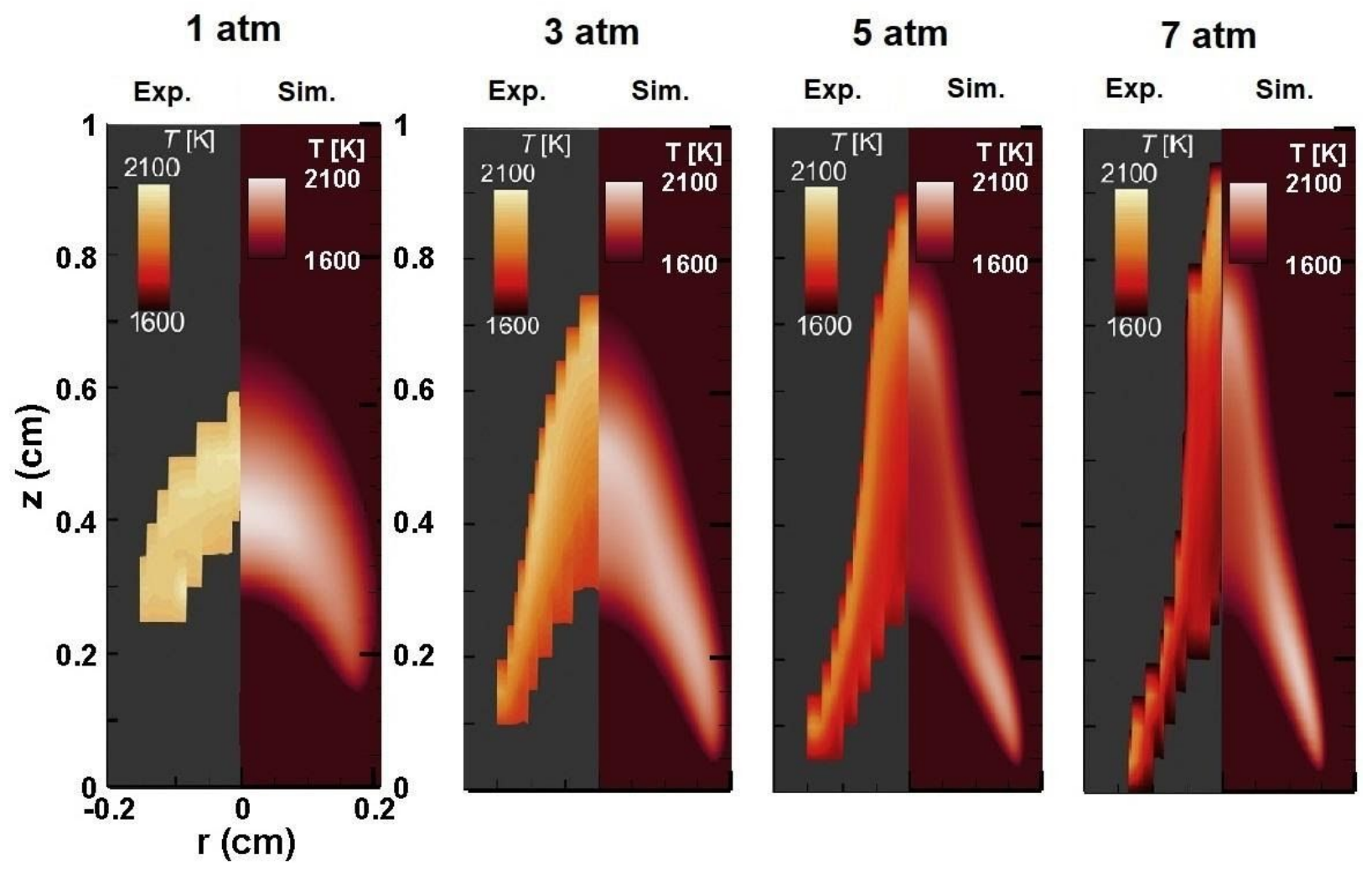

Figure 6: Comparison of temperature contours of the pure ethylene flames for the experimental study [9] and the present model at different pressures of 1, 3, 5, and $7 \mathrm{~atm}$ 

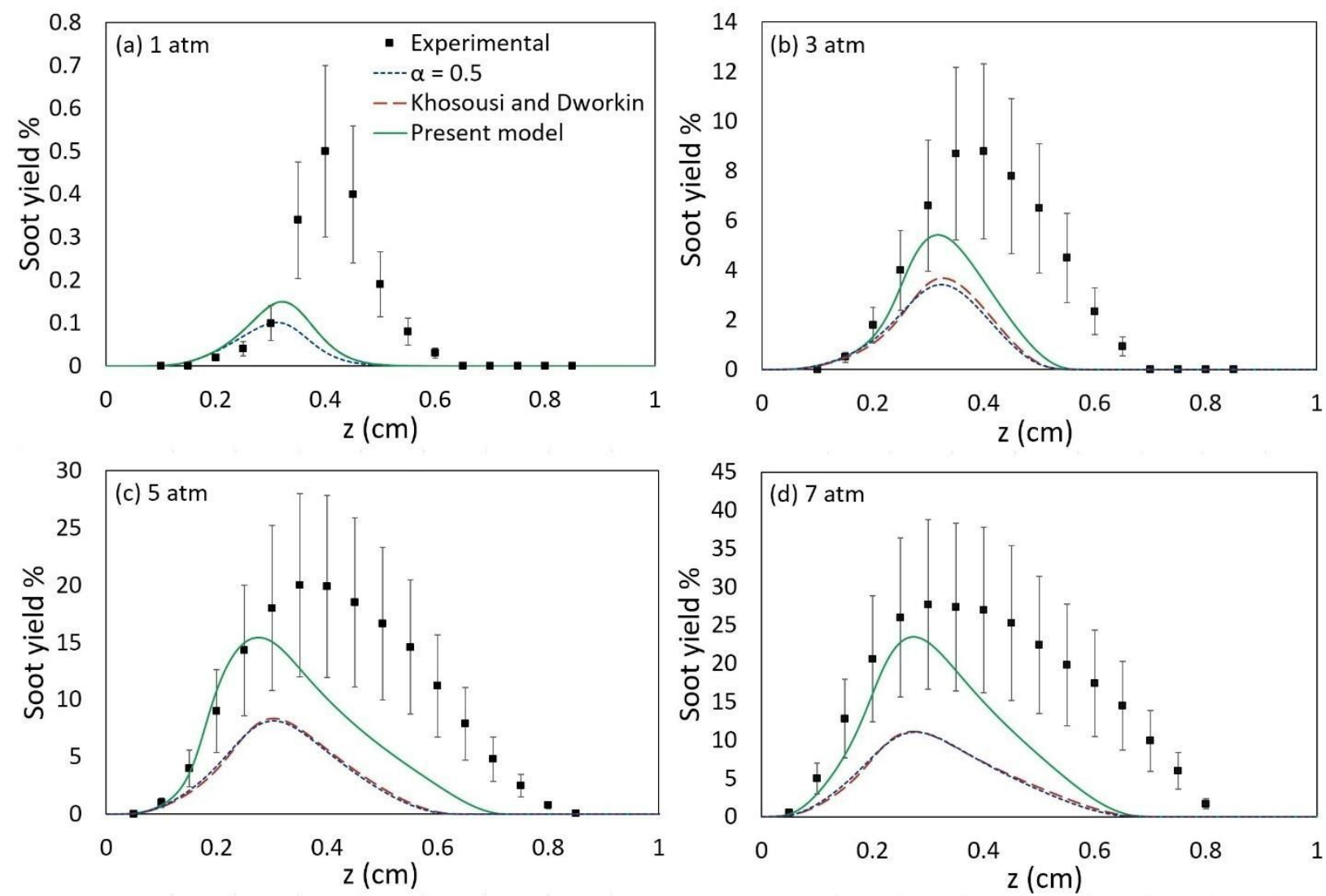

Figure 7: Comparison of soot yield percent as a function of the height-above-the-burner (HAB) $(z)$, for the experimental study [9], and simulations applying a constant $\alpha$ value of 0.5 , Khosousi and Dworkin model [1], and the present model for pure ethylene flames at different pressures a) 1 atm, b) $3 \mathrm{~atm}$, c) $5 \mathrm{~atm}$, and d) $7 \mathrm{~atm}$. 

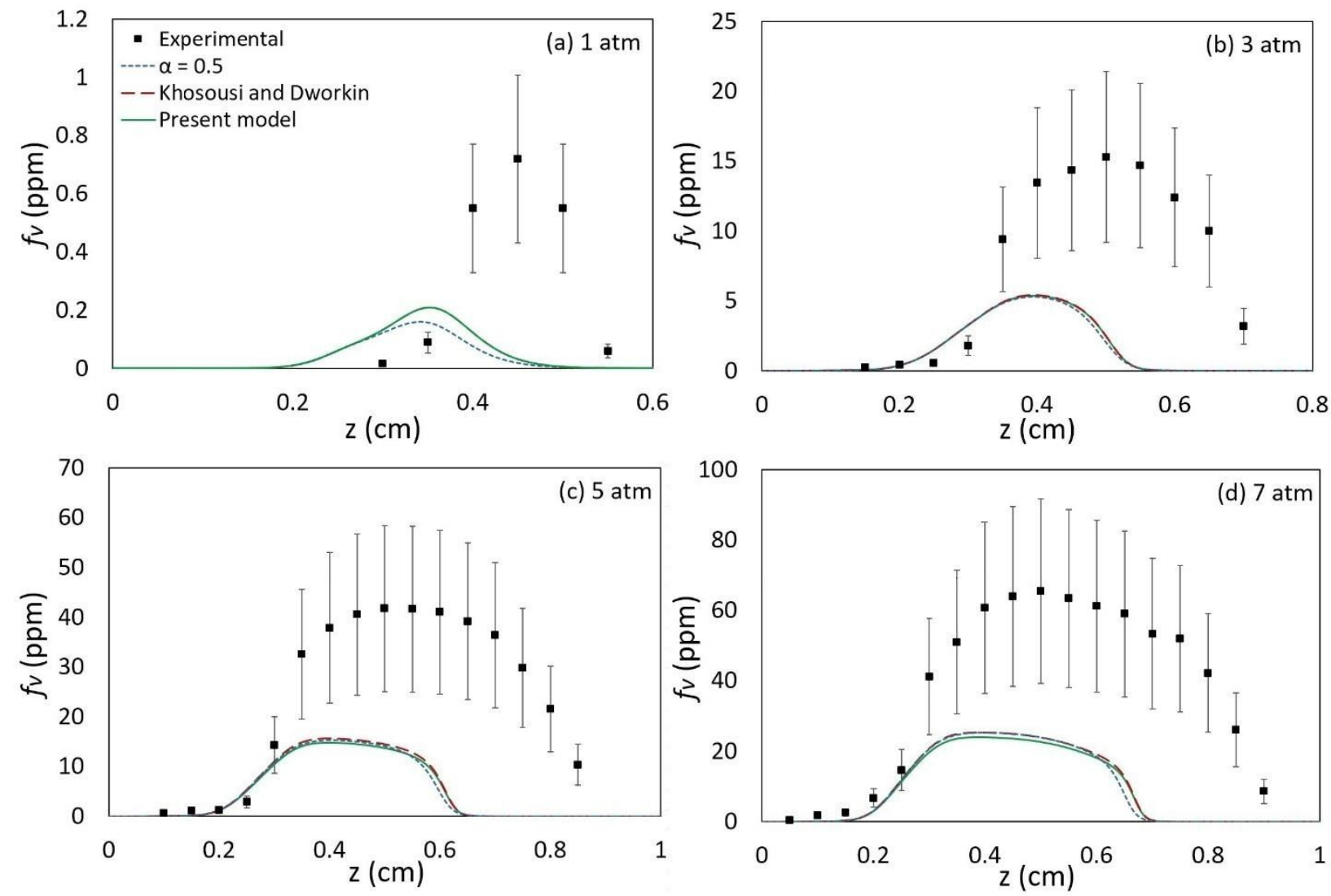

Figure 8: Comparison of $f_{v}$ versus the height-above-the-burner (HAB) $(z)$, along the centreline of the flame for the experimental study [9], and simulations applying a constant $\alpha$ value of 0.5 , Khosousi and Dworkin model [1], and the present model for pure ethylene flames at different pressures a) $1 \mathrm{~atm}$, b) $3 \mathrm{~atm}$, c) $5 \mathrm{~atm}$, and d) $7 \mathrm{~atm}$. 


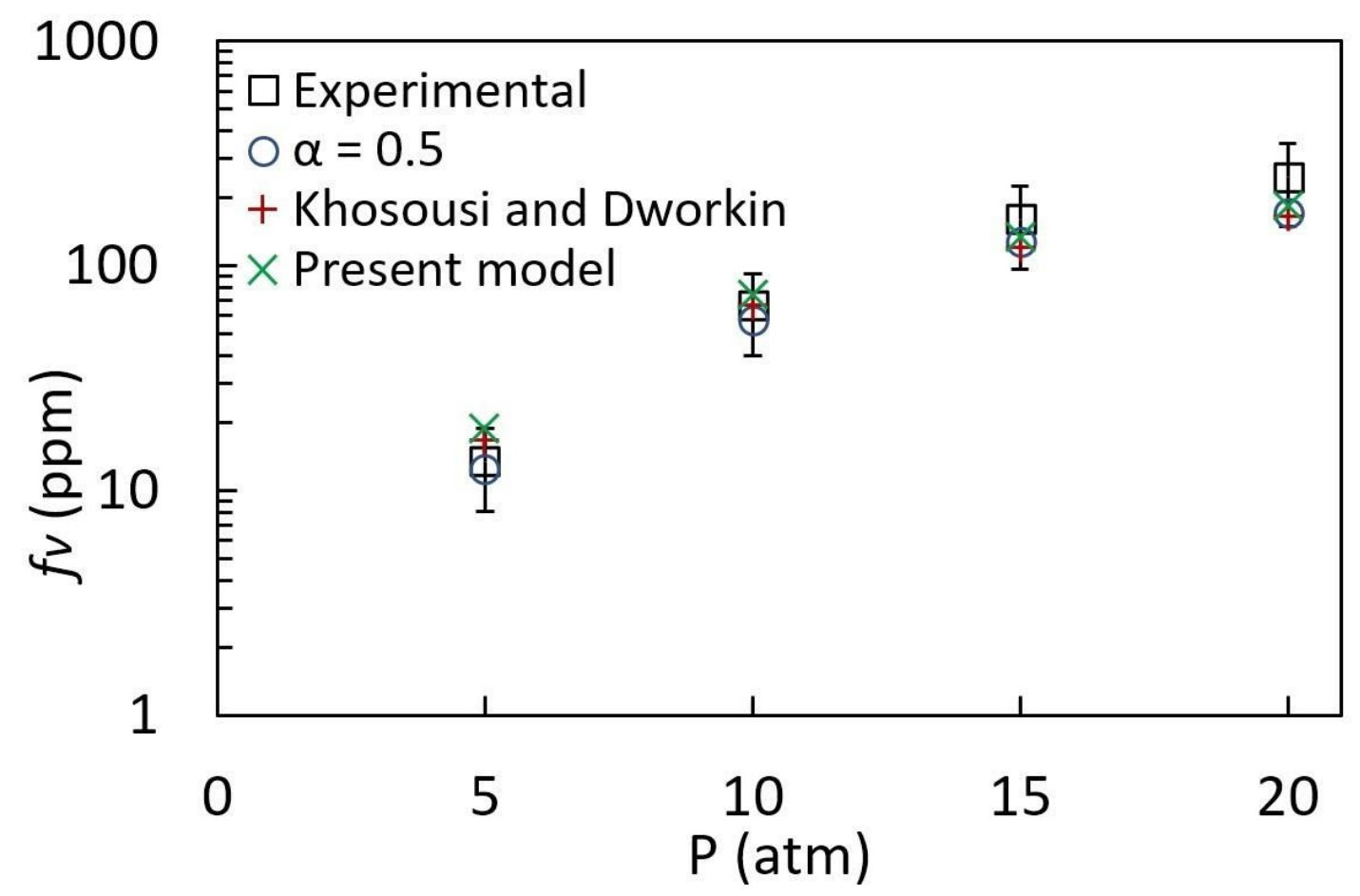

Figure 9: Comparison of global maximum soot volume fraction in the numerical study for a constant $\alpha$ value of 0.5, Khosousi and Dworkin model [1], and the present model, with the experimental study [9] for $\mathrm{N}_{2}$ diluted ethylene flames at different pressures of 5, 10, 15, and 15 atm. 


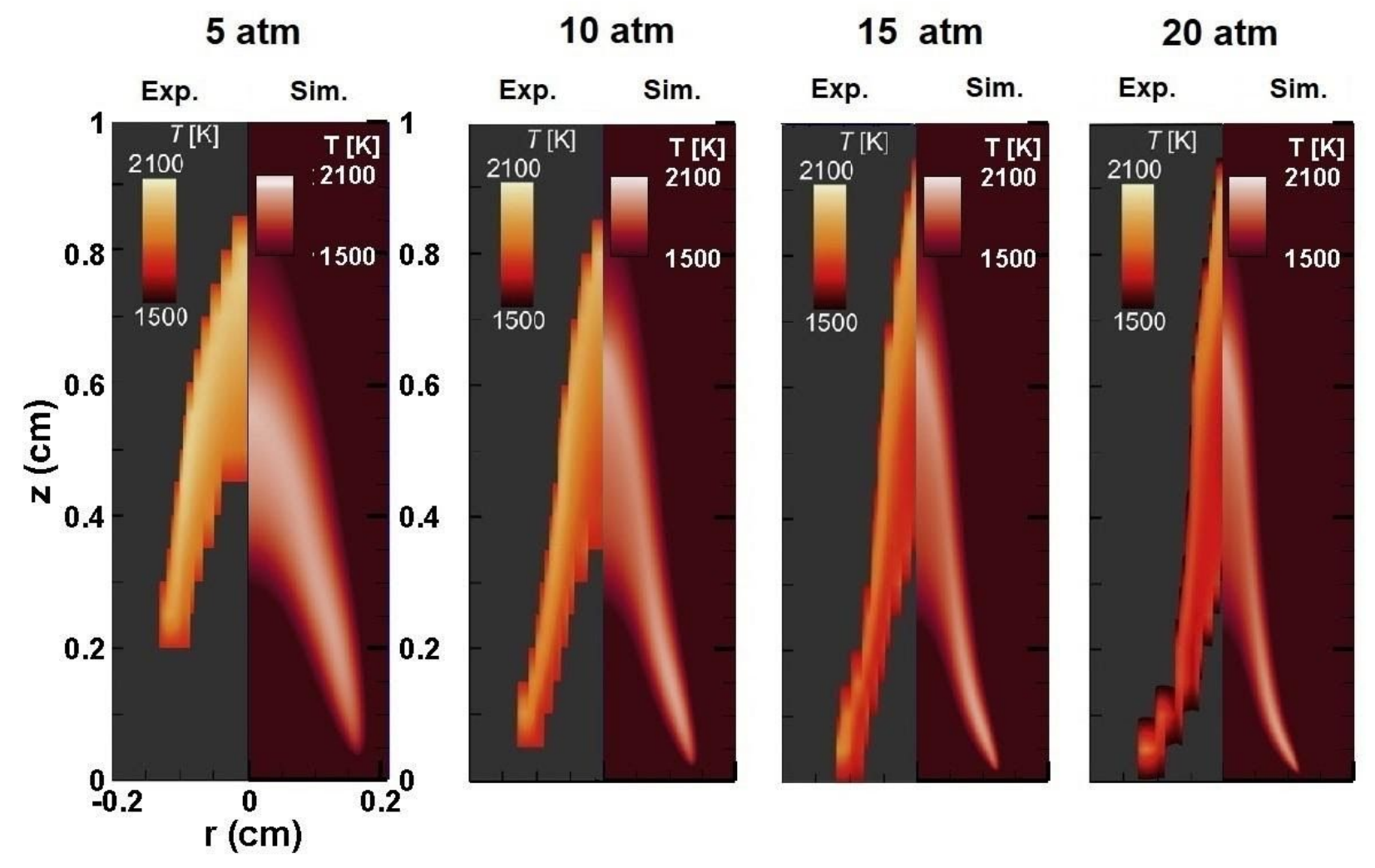

Figure 10: Comparison of temperature contours of the $\mathrm{N}_{2}$ diluted ethylene flames for the experiment [9] and simulations applying the present model at different pressures of 5, 10, 15, and $20 \mathrm{~atm}$. 

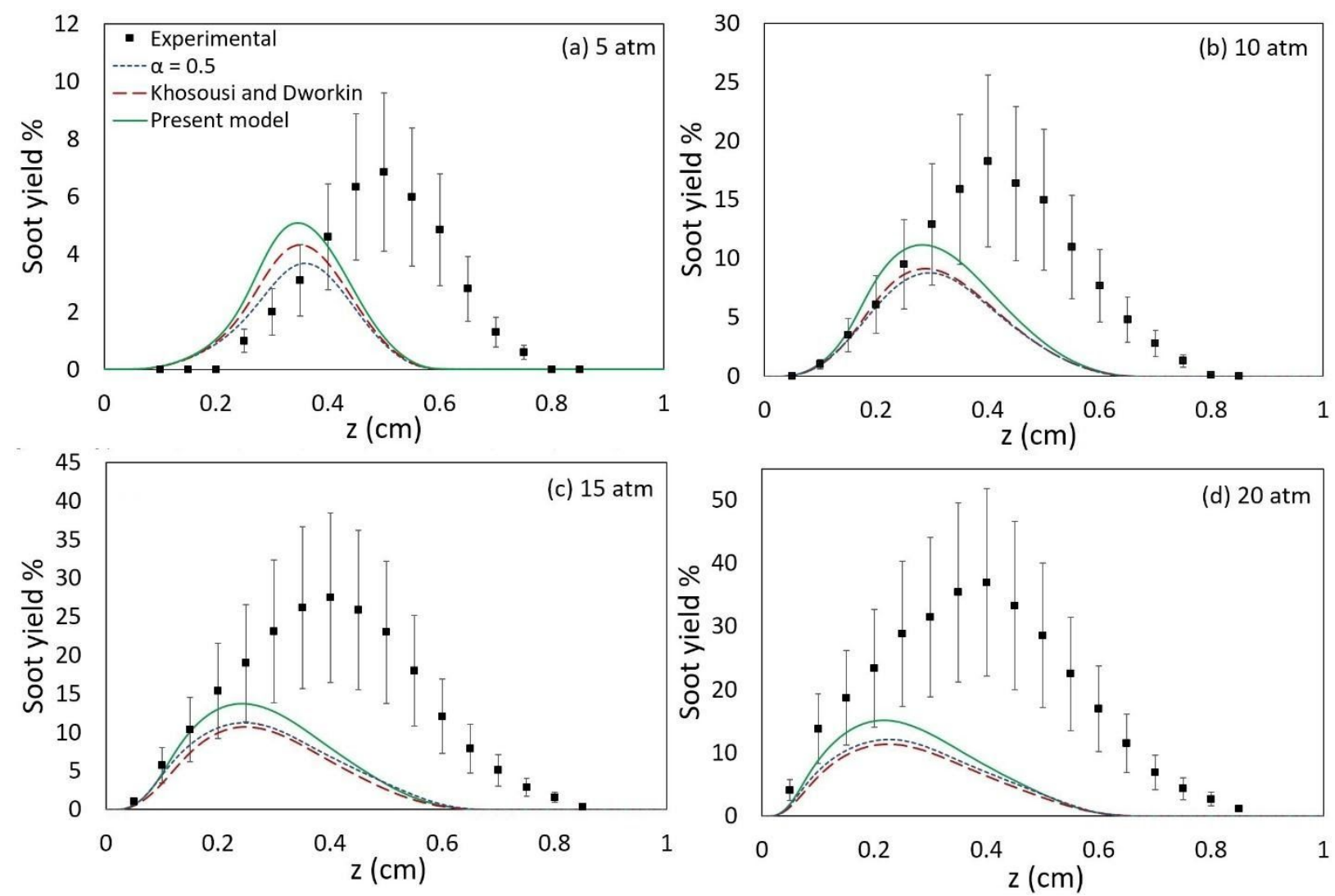

Figure 11: Comparison of soot yield percent as a function of the height-above-the-burner (HAB) $(z)$, for the experimental study [9] and simulations applying a constant $\alpha$ value of 0.5 , Khosousi and Dworkin model [1], and the present model for $\mathrm{N}_{2}$ diluted ethylene flames at different pressures a) $5 \mathrm{~atm}, \mathrm{~b}) 10 \mathrm{~atm}, \mathrm{c}) 15 \mathrm{~atm}$, and d) $20 \mathrm{~atm}$. 

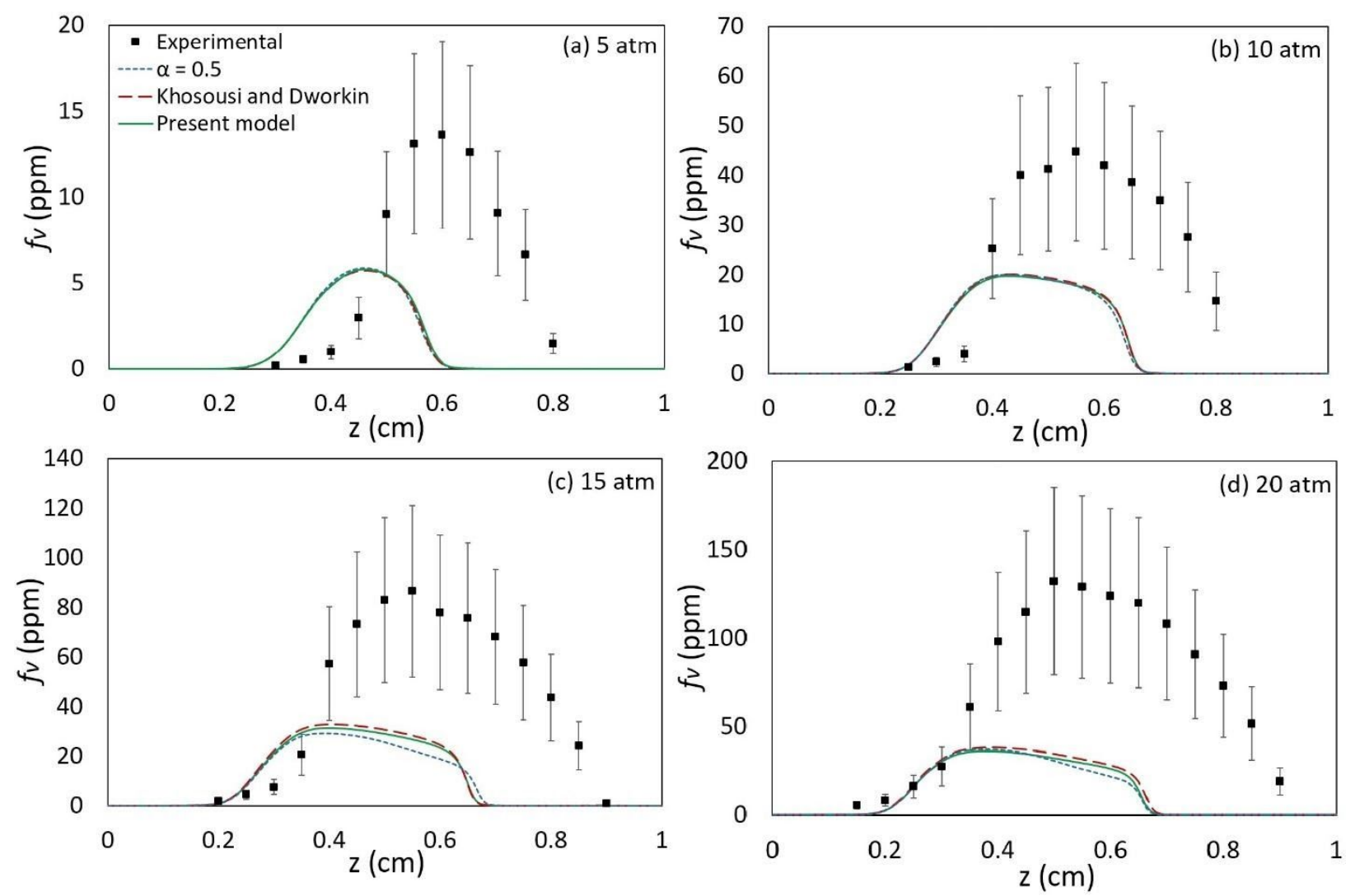

Figure 12: Comparison of $f_{v}$ versus the height-above-the-burner (HAB) $(z)$, along the centerline of the flame for the experimental study [9], and simulations applying a constant $\alpha$ value of 0.5 , Khosousi and Dworkin model [1], and the present model for the $\mathrm{N}_{2}$ diluted ethylene flames at different pressures a) $5 \mathrm{~atm}$, b) $10 \mathrm{~atm}$, c) $15 \mathrm{~atm}$, and d) $20 \mathrm{~atm}$. 